\title{
Farklı Element Katkılı Sodyum Fosfat Camlarının Sentez ve Karakterizasyonu
}

\section{Synthesis and Characterization of Sodium Phosphate Glasses Doped with Different Elements}

\author{
Serhat Keser ${ }^{1 *}$, Cengiz Tatar ${ }^{2}$, Tankut Ateş ${ }^{3}$, Turan İnce ${ }^{4}$, Ömer Kaygil1 ${ }^{5}$ \\ Geliş / Received: 26/02/2021 \\ Revize / Revised: 30/04/2021 \\ Kabul / Accepted: 09/06/2021 \\ ÖZET
}

Bu çalışmada, yaş kimyasal yöntemi ile üretilen $\mathrm{Ba}$ ve $\mathrm{Li}$ katkılı sodyum fosfat $\left(\mathrm{NaPO}_{3}\right)$ camları karakterize edildi. Ba katkılı numunelerin tamamının ve en yüksek Li katkısına sahip numunenin amorf yapıya sahip olduğu görüldü. Bunların haricindeki tüm numunelerin kristal yapıya sahip olduğu gözlendi. Fourier dönüşümlü kızılötesi (FTIR) spektroskopisi sonuçları $\mathrm{NaPO}_{3}$ yapısının oluşumunu desteklemektedir. Morfoloji, katkıların türü ve bunların miktarından etkilendi.

Anahtar Kelimeler- X-Işını Kırınımı (XRD), Morfoloji, Fourier Dönüşümlü Kızılötesi (FTIR)

\section{ABSTRACT}

In this study, $\mathrm{Ba}$ - and Li-doped sodium phosphate $\left(\mathrm{NaPO}_{3}\right)$ glasses synthesized by the wet chemical method were characterized. It was seen that all of the Ba-doped samples and the sample with the highest Li-doped had the amorphous structure. It was observed that all the samples except these had the crystal structure. Fourier transform infrared (FTIR) spectroscopy results support the formation of the $\mathrm{NaPO}_{3}$ structure. The morphology was affected by the kind of dopants and their amounts.

Keywords-X-Ray Diffraction (XRD), Morphology, Fourier Transform Infrared (FTIR)

\footnotetext{
1*Sorumlu yazar iletişim: serhatkeser@gmail.com (ORCID: 0000-0002-9678-1053)

Kimya Teknolojisi Bölümü, EOSB MYO, Fırat Üniversitesi 23119 Elazığ

2İletişim:ctatar@firat.edu.tr (ORCID: 0000-0002-0876-9071)

Fizik Bölümü, Fen Fakültesi, Fırat Üniversitesi 23119 Elazı̆̆

3lletişim: tankut ates@hotmail.com (ORCID: 0000-0002-4519-2953)

Mühendislik Temel Bilimleri Bölümü, Mühendislik ve Doğa Bilimleri Fakültesi, Malatya Turgut Özal Üniversitesi 44000

Malatya

4İletişim: trnince23@gmail.com (ORCID: 0000-0001-7885-1882)

Fizik Bölümü, Fen Fakültesi, Fırat Üniversitesi 23119 Elazı̆̆

5Iletișim: okaygili@firat.edu.tr (ORCID: 0000-0002-2321-1455)

Fizik Bölümü, Fen Fakültesi, Fırat Üniversitesi 23119 Elazığ
} 


\section{GíRiş}

İnorganik malzemelerin yüksek sıcaklığa maruz bırakılmasıyla üretilen seramik çeşitlerine “cam” adı verilir. Her ne kadar seramik türü olsalar da camlar, bazı fiziksel ve kimyasal özellikler bakımından seramiklerden farklılıklara sahiptirler. Örneğin, seramikler kristal yapıdadırlar ve sentez sırasında eriyene kadar isıtılıp, sertleşinceye kadar soğutulurlar. Buna karşılık camlar, kristal yapıya sahip değillerdir ve belirli bir düzene sahip olmayan inorganik yapıdadırlar. Kristal yapıya sahip moleküller düzenli bir yapıdayken, camın içerdiği moleküller katı oldukları halde rastgele yapıya sahiptirler. Camlar metalik, oksit ve oksit olmayan camlar şeklinde 3 ana gruba ayrılarak incelenirler. Fosfat camları, oksit cam grubunda yer alırlar. Elektriksel iletkenliklerinin ve ultraviyole geçirgenliklerinin yüksek olması, düşük sıcaklıklarda çalışılabilmeleri gibi fiziksel özellikleri fosfat camlarının diğer tür camlara nazaran daha çok tercih edilmelerine neden olmaktadır. Cam malzemeler, hem günlük hayatta hem de teknolojide kullanım alanı bulan vazgeçilmez malzemeler olarak kabul edilmektedirler [1].

Üç grupta incelenen camlar tek bileşene, iki bileşene ve ikiden daha fazla bileşene sahip olabilirler. Cam çeşitlerinin en önemlileri ise fosfat camları, soda-kireç silikat, boro-silikat, kurşun-silikat ve alümina-silikatlar olarak kabul edilmektedir [2, 3].

Fosfat camlarının yapısında alümina yüksek, alkali düşük oranlarda olduğunda bu camların yapısı silikat camlarına benzer. Silisyum (Si) iyonları 4 değerlikli iken, fosfor (P) iyonları ise 5 değerliklidir ve bu iyonların büyüklükleri birbirine benzer. Bu tür yapılarda $\mathrm{P}^{+5}$ iyonunun sahip olduğu fazla yükler, 3 değerlikli alüminyum (Al), 2 değerlikli kalsiyum $(\mathrm{Ca})$ ve magnezyum $(\mathrm{Mg})$ gibi iyonlar sayesinde nötralize edilirler. Saf haldeki katkısız fosfat camları, $\mathrm{P}^{+5}$ iyonu yapıya oksijen $(\mathrm{O})$ atomlarının girmesini sağladığı için yapı olarak zayıftırlar ve erime noktaları düşüktür. Ancak bu camların erime noktaları farklı katkılarla yükseltilebilir [2, 3].

Günümüzde fosfat camları uygun fiziksel ve kimyasal özellikleri sayesinde teknolojide önemli kullanım alanları bulmaya başlamıştır. Silikat camları ve/veya borat camları ile kıyaslandığında genleşme katsayılarının yüksekliği, yumuşama ve üretim sıcaklıklarının düşüklüğü gibi nispeten avantajlı ve önemli özellikler taşımaktadırlar [4]. Fosfat camları lazer camı olarak, hızlı şarj özelliğine sahip batarya malzemesi olarak, güneş pili olarak, biyomalzeme olarak ve nükleer atıkların taşınmasında potansiyel kullanım alanına sahiptirler [4-6].

Fosfat camları, oksit camları içinde yer alırlar ve şeffaflıklarının yüksek olması, erime noktalarının ve viskozitelerinin düşüklüğü, ultraviyole (veya morötesi, UV) iletimlerinin yüksekliği gibi önemli fiziksel özellikleri ile öne çıkmaktadırlar [7]. Bu tür özellikler fosfat camlarını fotonik uygulamalarda tercih edilebilir hale getirmektedir. Bu tip uygulamalar için nadir toprak elementleri ile katkılanan fosfat camları üretilmekte ve kullanılmaktadır. Örneğin neodimyum $\left(\mathrm{Nd}^{+3}\right)$ katkılanmış fosfat camları günümüzde üretilen en büyük lazer camı olarak bilinmektedir [8]. Ayrıca fosfat camlarının mekanik özelliklerinin mükemmele yakın olması, optik berraklıklarının ve biyo uyumluluklarının yüksek olması nedeniyle hem optik alanında hem de biyomedikal alanında kullanılmaktadırlar [9].

Bütün avantajlarının yanında fosfat camlarının bazı dezavantajları da vardır. Örneğin kimyasal kararlılıklarının zayıf olması, korozyona karşı dayanıksız olmaları endüstriyel uygulamalarını kısıtlamaktadır. Fosfat camlarının yapısına üretim aşamasında geçiş metallerinin oksitleri katkılandığı zaman kimyasal kararlılıklarının arttığı bilinmektedir. Bu katkılamalar sırasında fosfat camlarının yapısında P-O-P bağlarının yerini M-O-P bağları alarak yapısal değişiklikler meydana gelmektedir [4, 8]. Fosfat camlarıyla alakalı literatür incelendiğinde; Reis vd. [10] $\mathrm{Al}^{+3}$ ve $\mathrm{Fe}^{+3}$ gibi yüksek değerliğe sahip metallerin, Sirtokin vd. [11] sülfat $\left(\mathrm{SO}_{4}^{-2}\right)$ iyonlarının, Iturraran vd. [6] ise kalay bileşiklerinin fosfat camlarının yapısına katılmasıyla kimyasal kararlılıklarının arttırılabileceğini belirtmişlerdir. Keser vd. [12] Cu katkılanmış, Ateş vd. [13] ise Ag katkılanmış fosfat camlarının yapılarındaki değişimleri incelemiş ve bu metallerin fosfat camlarının yapısında önemli değişikliklere neden olduklarını belirlemişlerdir.

Bu çalışmada Ba ve Li katkılı iki farklı seri olarak hazırlanan $\mathrm{NaPO}_{3}$ camlarının üretimi ve üretilen bu cam örneklerinin XRD, SEM, EDX ve FTIR metotlarıyla karakterizasyonu gerçekleştirildi. 


\begin{tabular}{|c|c|c|}
\hline & $\begin{array}{l}\text { BŞEÜ Fen Bilimleri Dergisi } \\
8(1), 312-321,2021\end{array}$ & $\begin{array}{r}\text { BSEU Journal of Science } \\
\text { https://doi.org/10.35193/bseufbd.887424 }\end{array}$ \\
\hline $\begin{array}{l}\text { BilECEKSEYHEDEBALI } \\
\text { ONIVERSITESI }\end{array}$ & & 2458-7575 (https://dergipark.org.tr/tr/pub/bseufbd) \\
\hline
\end{tabular}

\section{MATERYAL VE YÖNTEM}

\section{A. Sentez}

$\mathrm{Bu}$ çalışmada kullanılan numuneler yaş kimyasal yöntemi ile hazırlandı. Şekil 1'de verilen akış diyagramında özetlenen sentez üç aşamadan (çözeltilerin hazırlanması, kurutulması ve ssıl işleme tabi tutulmaları) oluşmaktadır: Sodyum fosfat camlarının üretilmesinde kullanılan başlangıç kimyasalları sodyum fosfat monobazikdihidrat $\left(\mathrm{NaH}_{2} \mathrm{PO}_{4}\right.$, Sigma-Aldrich), lityum nitrat $\left(\mathrm{LiNO}_{3}\right.$, Merck) ve baryum nitrattan $\left(\mathrm{Ba}\left(\mathrm{NO}_{3}\right)_{2}\right.$, Merck) oluşmaktadır. İki farklı balon jojenin birinde (1-x) $\mathrm{M} \mathrm{NaH}_{2} \mathrm{PO}_{4}$ ve $x \mathrm{M} \mathrm{Ba}\left(\mathrm{NO}_{3}\right)_{2}$ çözeltileri hazırlandı. Li katkılı numuneler için $x \mathrm{M} \mathrm{LiNO}_{3}$ kullanıldı. Burada bahsi geçen $x$ değerleri hem $\mathrm{Ba}$ hem de Li katkılı numuneler için aynı olup, sırasıyla $0,0.01,0.02$ ve 0.03 'tür. Her iki çözelti için de çözücü olarak saf su kullanıldı. Bu çözeltiler bir beher içerisine boşaltılarak, bir manyetik karıştıııcı vasıtasıyla $300{ }^{\circ} \mathrm{C}$ sıcaklıkta 14 saat boyunca karıştıııldılar. $\mathrm{Bu}$ sürecin akabinde toz haline getirilen numuneler bir kül firını içerisine yerleştirildi. Ba katkılı numuneler $950{ }^{\circ} \mathrm{C}$ 'de 2 saat boyunca 1 sıl işleme tabi tutuldu. Li katkılı numuneler $875^{\circ} \mathrm{C}$ 'de 2 saat boyunca 1 sıl işleme tabi tutuldu. Isıl işlemler sonrası her bir seri için birer adet katkısız, üç adet $\mathrm{Ba}$ ve yine üç adet Li katkılı $\mathrm{NaPO}_{3}$ numuneleri üretildi. Ba katkılı numuneler, sırasıyla B1, B2, B3 ve B4 olarak isimlendirildi. Benzer biçimde, Li katkılı numuneler L1, L2, L3 ve L4 olarak adlandırıld.

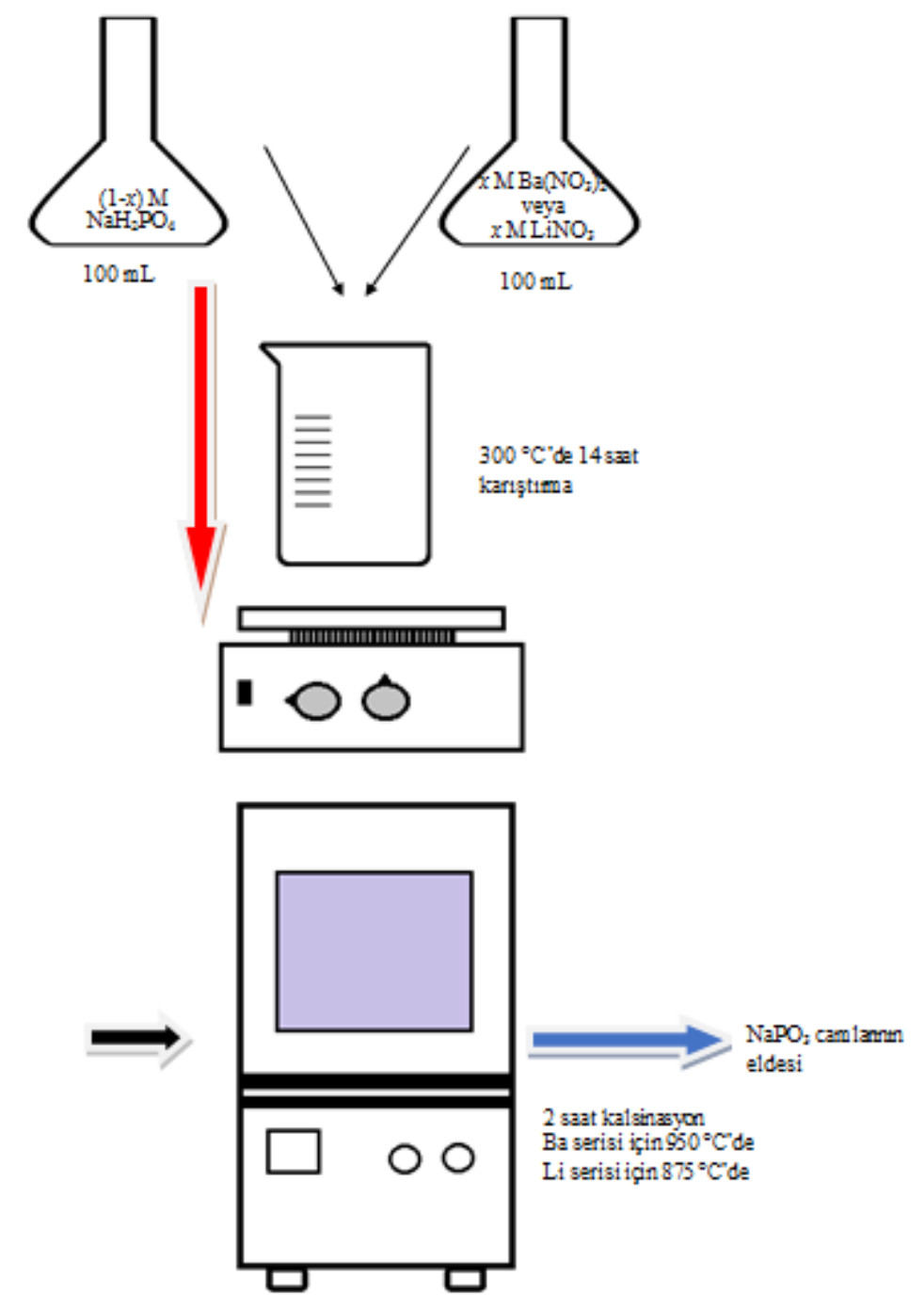

Şekil 1. Li ve Ba katkılı iki farklı seri halinde $\mathrm{NaPO}_{3}$ camlarının üretim safhaları 


\begin{tabular}{|c|c|c|}
\hline & $\begin{array}{l}\text { BŞEÜ Fen Bilimleri Dergisi } \\
8(1), 312-321,2021\end{array}$ & $\begin{array}{r}\text { BSEU Journal of Science } \\
\text { https://doi.org/10.35193/bseufbd.887424 }\end{array}$ \\
\hline $\begin{array}{l}\text { BuLECEKSEYHEDEBAL } \\
\text { UNIVERSITESI }\end{array}$ & & 2458-7575 (https://dergipark.org.tr/tr/pub/bseufbd) \\
\hline
\end{tabular}

\section{B. Karakterizasyon}

Üretilen numunelerin kristal yapı incelemeleri, Bruker D8 Advance cihazı kullanılarak X-ışını kırınımı (XRD) desenlerinin kaydedilmesi suretiyle gerçekleştirildi. Numuneler içerisindeki fonksiyonel grupların belirlenmesi, Perkin Elmer Spectrum One model spektrofotometre vasıtasıyla Fourier dönüşümlü kızılötesi (FTIR) spektrumlarının kaydedilmesi ile tamamlandı. Son olarak, JEOL JSM 7001F taramalı elektron mikroskobu kullanılmak suretiyle alınan SEM görüntülemeleri sayesinde morfolojik incelemeler yapıldı.

\section{BULGULAR VE TARTIŞMA}

\section{A. X-Işını Kırınımı Sonuçları}

Şekil 2'de verilen X-1şını kırınımı analizi sonuçlarından da açıkça görüldüğü üzere, üretilen hem katkısız numunenin hem de Ba-katkılı numunelerin hiçbirinde kristal yapıya işaret eden herhangi bir pike rastlanamamaktadır. Dört XRD deseninde de $10^{\circ}$ ile $40^{\circ}$ arasında belirgin bir yayvan pik mevcuttur ki bu durum hem katkısız hem de $\mathrm{Ba}$ katkılı numunelerin amorf yapıya sahip olduğunu göstermektedir. Önceki çalışmalarımızda farklı elementler katkılamak suretiyle kristal yapıya sahip katkılı ve katkısız sodyum fosfat numunelerini de göz önüne alarak, şunu söyleyebiliriz: Gerek katkılı gerekse katkısız halde üretilen sodyum fosfat camlarının kristalleşmesi, katkılanan elementin türü ve miktarından etkilenmesinin yanı sıra uygulanan ısıl işlemde kullanılan sicaklıktan da etkilenmektedir $[12,13]$.

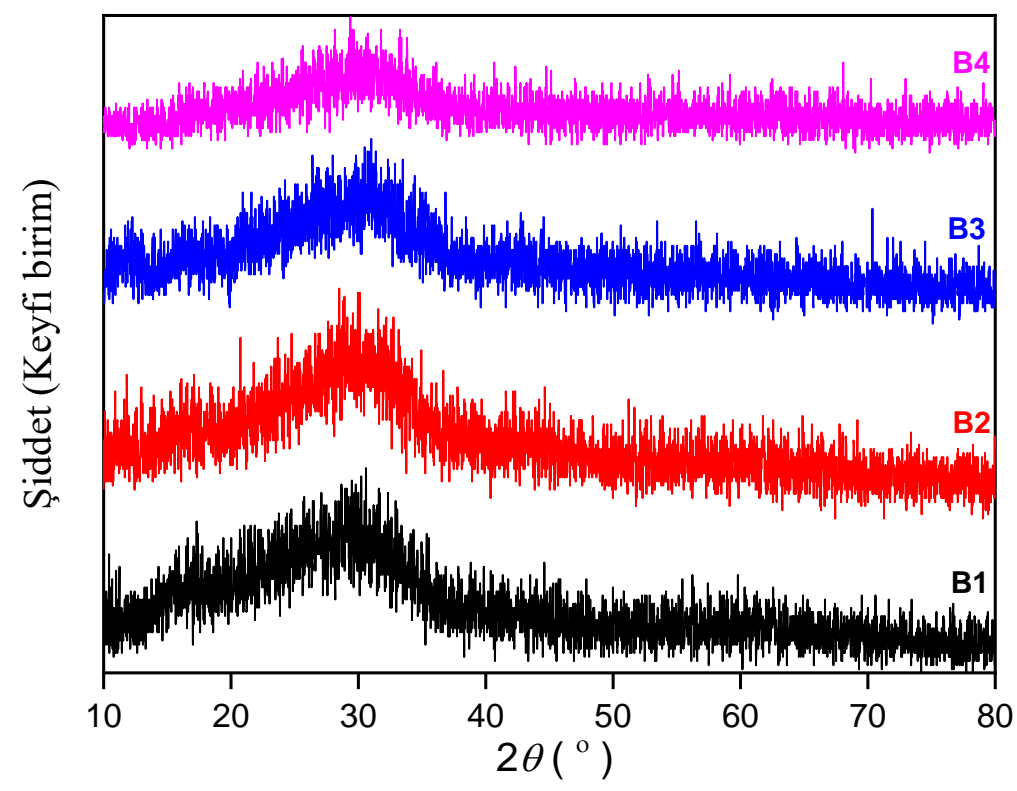

Şekil 2. Katkısız ve Ba-katkılı $\mathrm{NaPO}_{3}$ camlarının XRD desenleri

Li katkılı sodyum fosfat camlarına ait XRD desenleri Şekil 3'te gösterilmiştir. Gözlemlenen tek faz ortorombik kristal yapıdaki sodyum fosfat $\left(\mathrm{NaPO}_{3}\right.$, JCPDS PDF No: 11-0648) fazıdır. Katkısız numunenin (L1), düşük kristalleşmeye sahip olduğu gözlemlenen piklerin sayısına ve şiddetine bakıldığında görülebilmektedir. Katkısız numuneye nazaran, Li katkılı L2 ve L3 numunelerinin kristalleşmesi yüksektir. Fakat en yüksek Li katkısına sahip olan L4 numunesi için aynı durum söz konusu olmayıp, numunede gözlemlenen yayvan pikten de belli olacağı üzere amorf yapıya sahiptir. Aynı sentez şartları kullanılmasına rağmen, $\mathrm{Li}$ katkısının $\mathrm{NaPO}_{3}$ camlarının kristal yapısı üzerine etkisi oldukça fazladır. Yine Şekil 3'teki XRD desenlerine bakıldığında, Li katkısının bazı kristal düzlemlerinin belirgin olmasını sağlayacak biçimde açığa çıkmasına neden olduğu da görülebilir. 


\begin{tabular}{|c|c|c|}
\hline & $\begin{array}{l}\text { BŞEÜ Fen Bilimleri Dergisi } \\
8(1), 312-321,2021\end{array}$ & $\begin{array}{r}\text { BSEU Journal of Science } \\
\text { https://doi.org/10.35193/bseufbd.887424 }\end{array}$ \\
\hline ERS & & 2458-7575 (https://dergipark.org.tr/tr/pub/bseufbd) \\
\hline
\end{tabular}

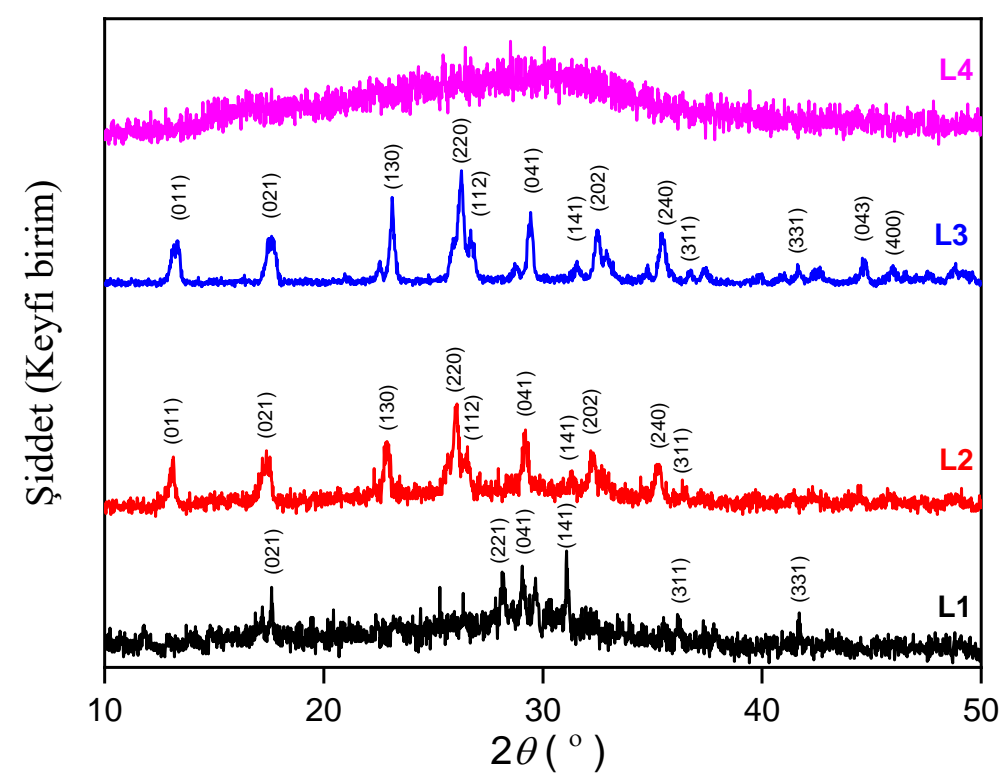

Şekil 3. Katkısız ve Li katkılı sodyum fosfat camlarının XRD desenleri

Şekil 2 ve Şekil 3'te verilen XRD desenleri arasında bariz farklılıklar vardır. Ba katkılı seride, referans numune de dahil olmak üzere tüm numuneler amorf yapı sergilemektedir. Fakat Li katkılı seride yalnızca en fazla Li katkısına haiz olan numune amorf yapı sergilerken, referans numune de dahil olmak üzere serinin geri kalan kısmının kristal yapı sergiledikleri tespit edilmiştir. Özellikle referans numunenin bir seride amorf diğer bir seri de kristal yapıya sahip oluşu anormal bir sonuç değildir. Bilindiği üzere camlar, amorf yapıya sahiptirler. Bununla birlikte, bazı camların uygun sıcaklık ve sürede kontrollü olarak kristalleşme özelliği de mevcuttur [14]. İki serinin üretimi aynı ısıl işlem süresinde yapılmış olmasına rağmen, ısıl işlem sıcaklıkları farklıdır. $\mathrm{Bu}$ da $\mathrm{NaPO}_{3}$ camlarının kristalleşmesinin her sıcaklıkta ve her katkı için gerçekleşmeyeceğinin göstergesi kabul edilebilir.

Ortorombik kristal yapıya ait örgü parametreleri $(a, b$ ve $c)$ ve birim hücre hacmi $(V)$ değerlerinin hesaplanmasında aşağıda verilen bağıntılar kullanıldı [12].

$$
\begin{aligned}
& \frac{1}{d^{2}}=\frac{h^{2}}{a^{2}}+\frac{k^{2}}{b^{2}}+\frac{l^{2}}{c^{2}} \\
& V=a b c
\end{aligned}
$$

Yukarıda verilen bağıntılarda geçen $h, k$ ve $l$ terimleri Miller indisleri olarak bilinir ve $d$ ise komşu iki düzlem arasındaki mesafeye karşılık gelmektedir. Bu denklemler yardımıyla hesaplanan $a, b, c$ ve $V$ değerleri Tablo 1'e kaydedilmiştir. İlgili tabloya bakıldığında L4 numunesi amorf yapıya sahip olduğu için doğal olarak bu dört parametrenin herhangi bir hesaplanmış değerine rastlanılamaz. İlgili tablodaki rapor edilen sonuçlara bakılacak olunursa; tüm örgü parametrelerinde Li katkısı ile birlikte sürekli bir düşüş meydana gelmektedir ve bunun neticesinde birim hücre hacminde de azalma tespit edilmektedir. Bu durum, $\mathrm{Na}^{+}$ve $\mathrm{Li}^{+}$iyonlarının iyonik yarıçapları ile ilişkilendirilebilir. $\mathrm{Na}^{+}$için bu değer $0.102 \mathrm{~nm}$ iken, $\mathrm{Li}^{+}$için $0.076 \mathrm{~nm}$ 'dir. Daha küçük iyonik yarıçapa sahip $\mathrm{Li}^{+}$iyonlarının, mevcut $\mathrm{Na}^{+}$iyonlarının yerini alması durumunda kristal örgüde bir küçülmenin olması gayet normal bir durum teşkil eder. Ayrıca hesaplanan bu parametrelerdeki değişimler, $\mathrm{Li}^{+}$iyonlarının $\mathrm{NaPO}_{3}$ yapı içerisine nüfuz ettiğinin bir göstergesi olarak kabul edilebilir.

Kristal büyüklüğü $(D)$ değeri, iyi bilinen Scherrer denklemi vasıtasıyla hesaplandı [12].

$$
D=\frac{0.9 \lambda}{\beta \cos \theta}
$$




\begin{tabular}{l|lr}
\hline \hline & $\begin{array}{l}\text { BŞEÜ Fen Bilimleri Dergisi } \\
8(1), 312-321,2021\end{array}$ & BSEU Journal of Science \\
& & \\
& & https://doi.org/10.35193/bseufbd. 887424
\end{tabular}

Denklemde verilen $\lambda \mathrm{X}$-ışınlarının dalga boyu, $\beta$ yarı maksimumdaki tam pik genişliği ve $\theta$ Bragg açısına karşılık gelmektedir. Kristal büyüklüğü değeri, L1, L2 ve L3 numuneleri için sırasıyla $20.86 \mathrm{~nm}, 15.25 \mathrm{~nm}$ ve $22.24 \mathrm{~nm}$ olarak hesaplanmıştır.

Kristalleşme yüzdesi $\left(X_{C} \%\right)$ hesabı aşağıdaki bağıntı kullanılmak suretiyle gerçekleştirildi [12]:

$$
X_{C} \%=\frac{\sum A_{C}}{\sum A_{C}+\sum A_{A}} \times 100
$$

Burada $\sum A_{C}$ ve $\sum A_{A}$ terimleri sırasıyla, kristal ve amorf yapıları temsil eden pikler altında kalan toplam alanlara karşılık gelmektedir. Tablo 1'deki değerlere bakılacak olunursa; numunelerin hesaplanan kristalleşme yüzdeleri L1, L2 ve L3 için sırasıyla \% 16.40, \% 47.76 ve \% 75.89 şeklindedir. L4 numunesinde kristalleşme mevcut değildir, yapı amorf halde kalmıştır.

Tablo 1. Katkısız ve Li katkılı sodyum fosfat camlarına ait kristal yapı parametrelerinin hesaplanan değerleri

\begin{tabular}{ccccccc}
\hline Numune & $\boldsymbol{a}(\mathbf{n m})$ & $\boldsymbol{b}(\mathbf{n m})$ & $\boldsymbol{c}(\mathbf{n m})$ & $\boldsymbol{V}\left(\mathbf{n m}^{3}\right)$ & $\boldsymbol{D}(\mathbf{n m})$ & $\boldsymbol{X}_{\boldsymbol{C}}(\mathbf{\%})$ \\
\hline L1 & 0,7947 & 1,3439 & 0,7867 & 0,8402 & 20,86 & 16,40 \\
L2 & 0,7928 & 1,3333 & 0,7808 & 0,8253 & 15,25 & 47,76 \\
L3 & 0,7891 & 1,3202 & 0,7696 & 0,8018 & 22,24 & 75,89 \\
L4 & - & - & - & - & - & - \\
\hline
\end{tabular}

Tıpkı Li katkılı seriye ait L4 numunesinde olduğu gibi Ba katkılı serinin tüm numuneleri de amorf yapıya haiz olduğundan, bu numuneler için de $\mathrm{a}, \mathrm{b}, \mathrm{c}, \mathrm{V}, \mathrm{D}$ ve $\mathrm{X}_{\mathrm{C}} \%$ parametrelerinin hesaplanması söz konusu değildir.

\section{B. FTIR Sonuçlart}

Şekil 4 ve Şekil 5'te verilen Fourier dönüşümlü kızılötesi (FTIR) spektrumlarında fosfat grubunun ve adsorbe olmuş suyun titreşim modlarına ait bantlara rastlanmaktadır. Bunlardan fosfat grubuna karşılık gelen bantlar Ba katkılı seri için sırasıyla $533 \mathrm{~cm}^{-1}, 877 \mathrm{~cm}^{-1}, 1103 \mathrm{~cm}^{-1}$ ve $1384 \mathrm{~cm}^{-1}$ de tespit edilmiştir [15-18]. Li katkılı seri için fosfat grubuna ait bantlar $520 \mathrm{~cm}^{-1}, 1117 \mathrm{~cm}^{-1}$ ve $1384 \mathrm{~cm}^{-1}$ 'de gözlenmiştir. Ba katkılı seri için $1637 \mathrm{~cm}^{-1}$ 'de tespit edilen bant ve $3453 \mathrm{~cm}^{-1}$ 'de gözlemlenen daha geniş bant, adsorbe olan suyun titreşim modlarına karşılık gelmektedir [19]. Li katkılı seri için bahsi geçen bantlar $1646 \mathrm{~cm}^{-1}$ ve $3461 \mathrm{~cm}^{-1}$ 'de tespit edilmiştir.

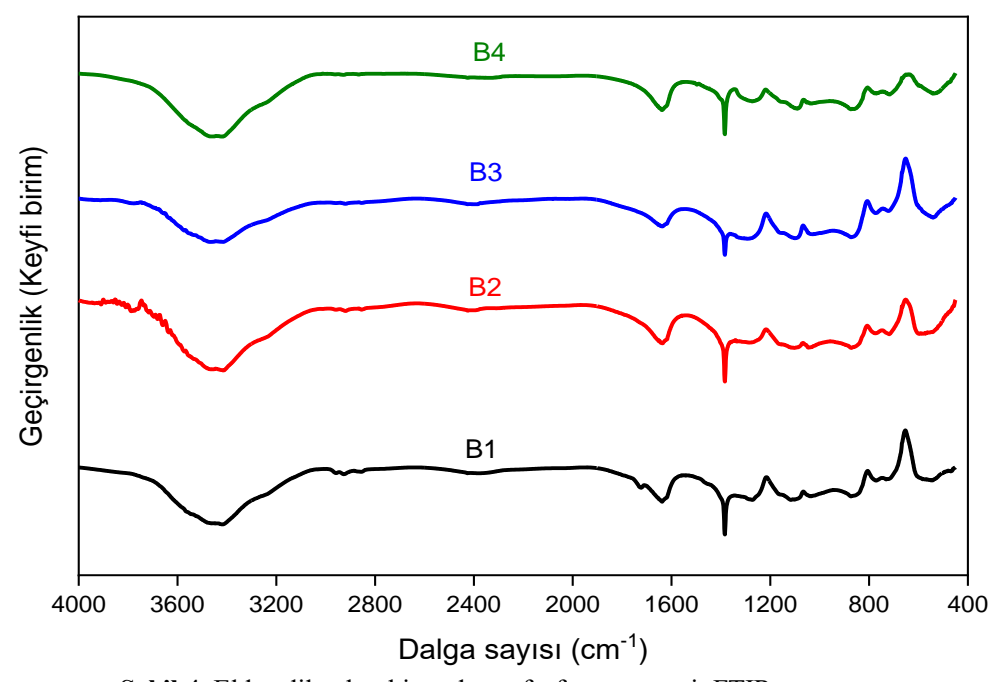

Şekil 4. Elde edilen her bir sodyum fosfat camına ait FTIR sonucu 


\begin{tabular}{l|lr}
\hline \hline & $\begin{array}{l}\text { BŞEÜ Fen Bilimleri Dergisi } \\
8(1), 312-321,2021\end{array}$ & BSEU Journal of Science \\
& & \\
& & https://doi.org/10.35193/bseufbd. 887424
\end{tabular}

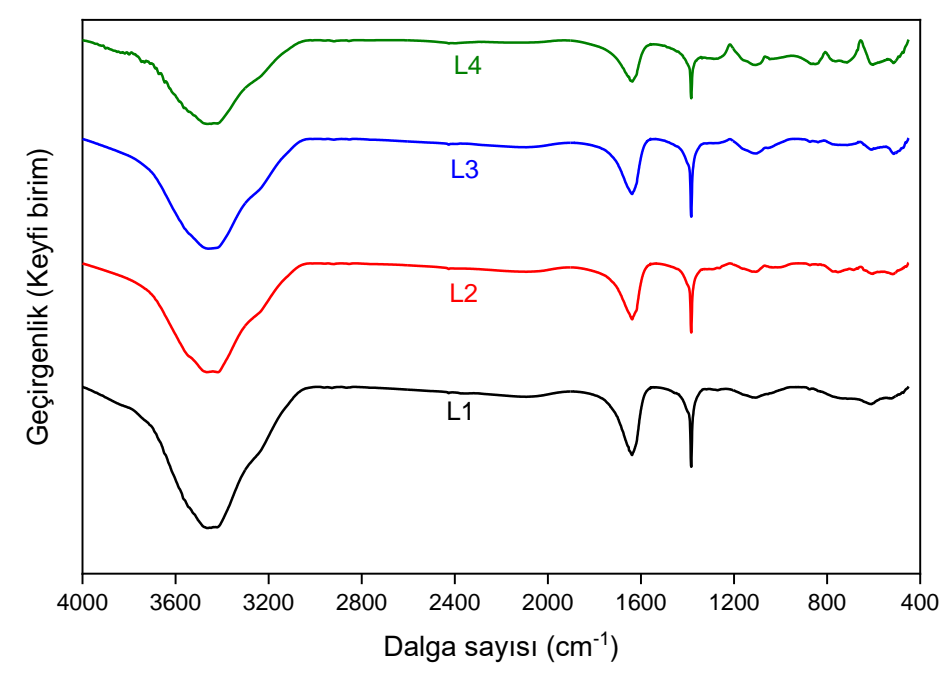

Şekil 5. Katkısız ve Li katkılı sodyum fosfat camlarının FTIR sonuçları

\section{Morfolojik Analizler}

Şekil 6'da verilen, numunelere ait SEM görüntülerinin ve bu görüntü alınan bölgelerin elementel analizini veren EDX raporuna bakılacak olunursa şunları söylemek mümkündür. Morfolojik anlamda, Ba katkılanmış ve katkılanmamış numuneler arasında göze çarpan ciddi bir farklılık bulunmamaktadır. Görüntü alınan bölgelere ait EDX raporları da numuneler içerisinde beklendiği gibi katkısız numunede $\mathrm{Na}, \mathrm{P}$ ve $\mathrm{O}$ ve katkılı numunelerde ise $\mathrm{Na}, \mathrm{P}, \mathrm{O}$ ve $\mathrm{Ba}$ elementlerinin tespit edildiğini göstermektedir. Bunların dışında fazladan bir elementin mevcut olmadığı da tespit edilmiştir. Dört numune için de $\mathrm{Na}$ ve P'nin atomik yüzdelerinin birbirine yakın olduğu bulunmuştur. Ba elementinin atomik yüzdesinin katkılamayla orantılı olarak arttığı tespit edilmiştir.

Katkısız ve Li katkılı olarak üretilen sodyum fosfat camlarına ait SEM görüntüleri ve EDX analiz raporu Şekil 7'de verilmiş̧ir. Li katkısının morfolojik anlamda çok ciddi bir değişim meydana getirdiği söylenememekle birlikte, özellikle L3 ve L4 numunelerinde nano-boyuttaki parçacıklara, yüzeyler üzerinde ve boşluk ve/veya çatlaklar arasında rastlamak mümkündür. EDX analiz sonuçları, numunelerde $\mathrm{Na}$, P ve $\mathrm{O}$ elementlerinin bulunduğuna ve kirlilik olarak kabul edilebilecek fazladan bir elementin tespit edilmediğine işaret etmektedir. EDX analizörü tarafından Li elementinin tespiti mümkün olmadığından, Li miktarının elementel bileşime ne doğrultuda bir etki yaptığı hakkında bir şey söylenmesi mümkün değildir. Ayrıca, EDX sonuçlarında gözlemlenen elementlerin atomik bileşimlerine bakıldığında, sonuçların her bir numune için $\mathrm{NaPO}_{3}$ yapısının oluşumunu destekler nitelikte olduğu söylenebilir. 


\begin{tabular}{|c|c|c|}
\hline & $\begin{array}{l}\text { BŞEÜ Fen Bilimleri Dergisi } \\
8(1), 312-321,2021\end{array}$ & $\begin{array}{r}\text { BSEU Journal of Science } \\
\text { https://doi.org/10.35193/bseufbd.887424 }\end{array}$ \\
\hline $\begin{array}{l}\text { BuLECLIKSEYH EDEBALL } \\
\text { ONIVERSITESI }\end{array}$ & & 2458-7575 (https://dergipark.org.tr/tr/pub/bseufbd) \\
\hline
\end{tabular}
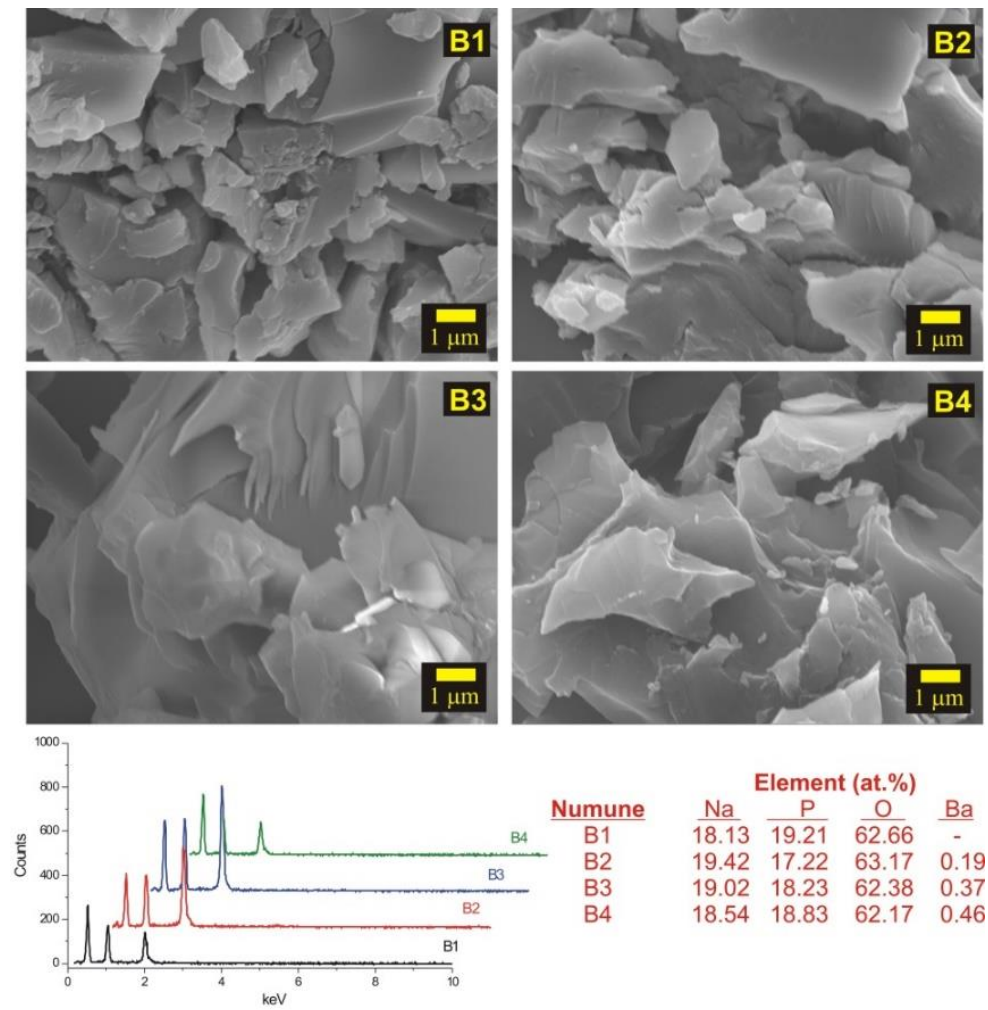

Şekil 6. Ba katkılı numunelere ait SEM fotoğrafları ve görüntü alınan bölgelere ait EDX analiz raporu
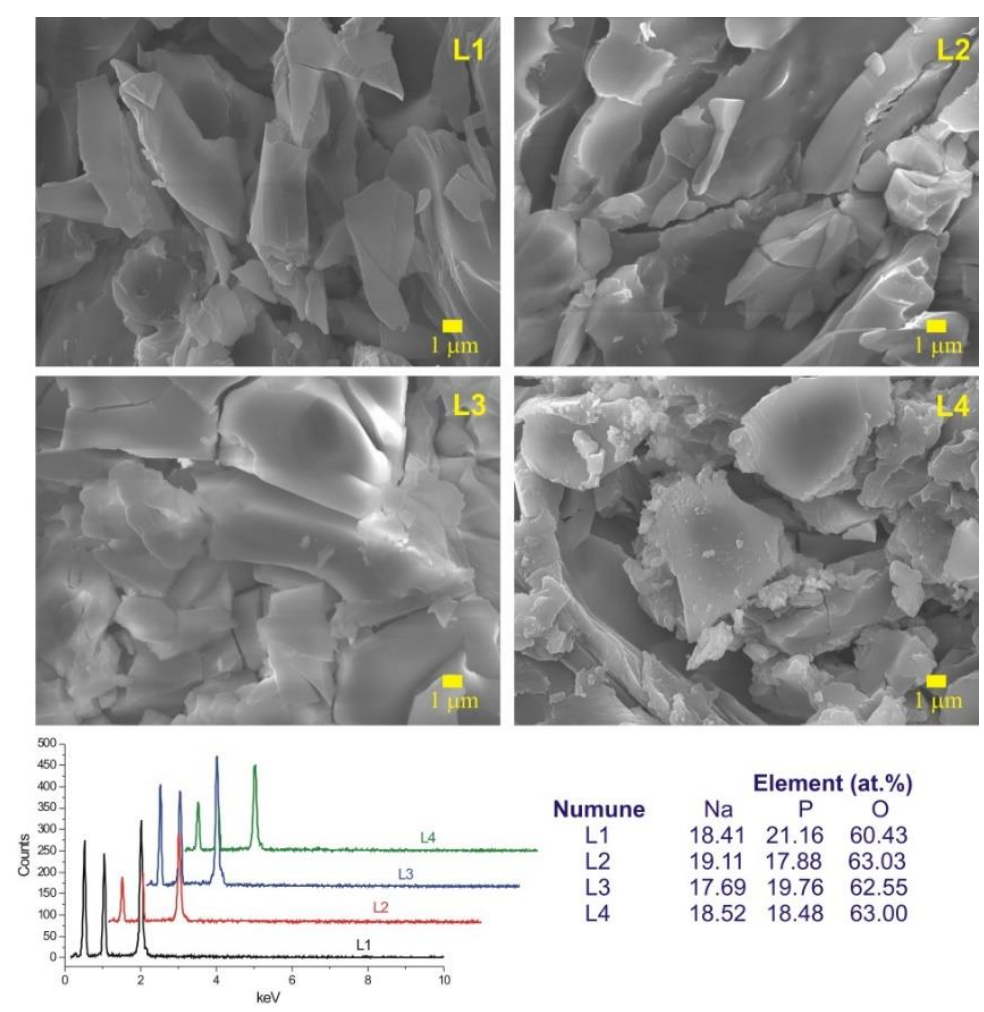

Şekil 7. Li katkılı numunelere ait SEM görüntüleri ve EDX analiz raporu 


\section{SONUÇ}

Bu çalışmada, katkısız ve $0.01,0.02$ ve $0.03 \mathrm{M}$ Ba ve yine aynı oranlara Li katkılanmış sodyum fosfat camlarının üretimi yaş kimyasal yöntem vasıtasıyla yapılmış, daha sonra bu camların FTIR, XRD, SEM ve EDX teknikleri ile karakterizasyonları gerçekleştirilmiştir.

Ba katkılı seri için şu sonuçlara varılmıştır: Üretilen bütün numunelerin amorf yapıda olduğu belirlenmiştir. FTIR sonuçları sentez sonucunda sodyum fosfat camları oluştuğunu göstermiştir. Sentezlenen örneklerin SEM incelemelerinde, Ba katkısının ve bu katkılamanın miktarının morfoloji üzerinde etkiye sahip olduğunu gözlenmiştir. Son olarak EDX sonuçlarına bakıldığında, üretilen numunelerin sentez öncesinde hesaplanan teorik elementel bileşime yakın olduklarını ve Ba elementinin fosfat camlarının yapısına katıldığını görülmektedir.

Li katkılı numuneler içinse şu sonuçlara ulaşmak mümkündür: Li katkısının kristalleşme miktarı, örgü parametreleri ve kristal büyüklügüu üzerinde etkileri olduğu belirlenmiştir. L1 numunesinin düşük kristalleşmeye, L2 ve L3 numunelerinin ise yüksek kristalleşmeye sahip olduğu, L4 numunesinin ise amorf yapıda olduğu anlaşılmıştır. FTIR analizleri incelendiğinde elde edilen sonuçların sodyum fosfat camlarının oluşumunu desteklediği gözlenmiştir. Üretilen numunelerin morfolojik değerlendirmelerinde, Li katkılamasının morfoloji üzerinde etkili sonuçlara sebep olduğunu belirlenmiştir. Elementel analiz sonuçları, elde edilen ürünlerin sentez öncesinde hesaplanan elementel bileşime sahip olduklarını ve Li elementinin fosfat camlarının yapısına nüfuz ettiğini göstermektedir.

\section{KAYNAKLAR}

[1] Çetinkaya Çolak, S. (2009). Geçis metal iyonları katkılı sodyum-fosfat camların elektrik, optik, yapısal, yüzeysel ve termal özellikleri. Doktora Tezi, Fizik Bölümü, Osmangazi Üniversitesi, Eskişehir.

[2] Orbay, B. (2007). Potasyum mikası ve kordierit içeren işlenebilir cam seramiklere çekirdeklenme katalisti $\left(\mathrm{TiO}_{2}\right)$ ilavesinin kristalizasyon davranışı ve elektriksel özellikler üzerindeki etkisinin incelenmesi. Yüksek Lisans Tezi, Metalurji ve Malzeme Mühendisliği Anabilim Dalı, Fen Bilimleri Enstitüsü, İstanbul Teknik Üniversitesi, İstanbul.

[3] Çekli, C. (2005). Sodyum-potasyum mikası ve florapatit içeren işlenebilir cam seramiklerin kristalizasyon davranışları, işlenebilirlik özellikleri ve biyoaktivite karakterizasyonu. Yüksek Lisans Tezi, Metalurji ve Malzeme Mühendisliği Anabilim Dalı, Fen Bilimleri Enstitüsü, İstanbul Teknik Üniversitesi, İstanbul.

[4] Choudhary, B. P. \& Singh N. B. (2016). Properties of silver phosphate glass in the presence of nanosize cobalt and nickel oxides. Journal of Non-Crystalline Solids, 440, 59-69.

[5] Liang, X., Li, H., Wang, C., Yu, H., Li, Z. \& Yang, S. (2014). Physical and structural properties of calcium iron phosphate glass doped with rare earth. Journal of Non-Crystalline Solids, 402, 135-140.

[6] Iturraran, N., Huraux, K., Bao, Y., Gawne, D. T. \& Guilment, J. (2018). Effect of melting parameters during synthesis on the structure and properties of tin fluoride phosphate glasses. Journal of Non-Crystalline Solids, $489,64-70$.

[7] Chanthima, N., Tariwong, Y., Djamal, M., Kaewkhao, J. \& Sangwaranatee, N. (2018). Physical, optical and luminescence properties of $\mathrm{Sm}^{3+}$ doped lithium aluminium phosphate glass system. Materials Today: Proceedings, 5, 15066-15071.

[8] Novais, A.L.F., Dantas, N.O., Guedes, I. \& Vermelho, M.V.D. (2015). Spectroscopic properties of highly Nd-doped lead phosphate glass. Journal of Alloys and Compounds, 648, 338-345.

[9] Kim, K., Rahimi, S. K., Alam, T. M., Sorte, E. G. \& Otaigbe, J. U. (2018). Unexpected effects of inorganic phosphate glass on crystallization and thermo-rheological behavior of polyethylene terephthalate. Polymer, $154,135-147$.

[10] Reis, S.T., Karabulut, M. \& Day, D. E. (2001).Chemical durability and structure of zinc-iron phosphate glasses. Journal of Non-Crystalline Solids, 292, 150-157.

[11] Sirotkin, S., Meszaros, R. \& Wondraczek, L. (2012).Chemical stability of $\mathrm{ZnO}-\mathrm{Na}_{2} \mathrm{O}-\mathrm{SO}_{3}-\mathrm{P}_{2} \mathrm{O}_{5}$ glasses. International Journal of Applied Glass Science, 3, 44-52.

[12] Keser, S., Ateş, T. \& Kaygılı, O. (2019). Cu katkılı $\mathrm{NaPO}_{3}$ camlarının sentez ve karakterizasyonu. Bilecik Şeyh Edebali Üniversitesi Fen Bilimleri Dergisi, 6(2), 552-561.

[13] Ateş, T., Keser, S. \& Kaygıllı, O. (2019). Ag katkılı $\mathrm{NaPO}_{3}$ camları: Sentez ve karakterizasyon. Bitlis Eren Üniversitesi Fen Bilimleri Dergisi, 8(2), 428-434. 
[14] Kaygıl1, Ö. (2005). Radyasyonun cam-seramik maddelerin kristalleşme ve mekanik özellikleri üzerine etkisi. Yüksek Lisans Tezi, Fırat Üniversitesi, Fen Bilimleri Enstitüsü, Elazığ.

[15] Jha, P. K., Pandey, O. P. \& Singh, K. (2016). Non-isothermal crystallization kinetics of $\mathrm{K}_{2} \mathrm{O}$ modified sodium-phosphate glasses. Journal of Non-Crystalline Solids. 440, 76-84.

[16] Basak, A., Ramrakhiani, L., Ghosh, S., Sen, R. \& Mandal, A. K. (2018). Preparation of chromium doped phosphate glass adopting microwave irradiation and comparative analysis of properties with conventional glass. Journal of Non-Crystalline Solids. 500, 11-17.

[17] Stefanovsky, S. V., Stefanovsky, O. I., Kadyko, M. I. \& Nikonov, B. S. (2018). Sodium aluminum-iron phosphate glass-ceramics for immobilization of lanthanide oxide wastes from pyrochemical reprocessing of spent nuclear fuel. Journal of Nuclear Materials. 500, 153-165.

[18] Liu, J., Zhu, Y., Wang, F., Liao, Q., Zhu, H., Deng, Y. \& Zhu, Y. (2018). Properties and structural features of iron sodium phosphate glasses containing neodymium oxide. Journal of Non-Crystalline Solids. 500, 9297.

[19] Abdelghanyi, A. M., El-Damrawi, G., Oraby, A. H. \& Madshal, M. A. (2018). Optical and FTIR structural studies on CoO-doped strontium phosphate glasses. Journal of Non-Crystalline Solids. 499, 153-158. 